\title{
O Gênero na Imigração: Redefiniç̧ões de Papéis e Dinâmicas Étnicas
}

\author{
Gender on Immigration: Redefining Roles and Ethnic Dynamics
}

João Carlos Tedesco

Universidade de Passo Fundo

jctedesco@upf.br

\section{Resumo}

O texto analisa aspectos da imigração brasileira no norte e nordeste da Itália; busca dar ênfase à questão de gênero no horizonte do trabalho, no convívio familiar e em suas dinâmicas transnacionais. O mesmo demonstra que os processos que envolvem a migração brasileira para a Itália redefinem e reconfiguram papéis de gênero, bem como possuem influência das redes étnicas que vão se constituindo entre os dois países.

Palavras-chave: imigração, gênero, redes étnicas.

\begin{abstract}
The paper analyzes aspects of Brazilian immigrants in the North and Northeast of Italy and it seeks to emphasize on gender issues at work, in family life and their transnational dynamics. This paper also shows that the processes surrounding Brazilian migration to Italy redefine and reshape gender roles as well as they have influence of the ethnic networks that are being constituted between the two countries.
\end{abstract}

Keywords: Immigration, gender, ethnic networks 


\section{Introdução}

Pouco se fala das questões de gênero no processo migratório, assim como especificamente das mulheres, a não ser para enquadrá-las em algumas dimensões negativas ligadas a prostituição, a facilidade de exploração de seu trabalho pelos que as contratam, a desconfiança em relação a problemas familiares em sua opção pela migração e, portanto, de fuga do espaço de origem etc. As migrações foram representadas como dinâmicas orientadas e viabilizadas pela esfera masculina; o homem abrindo o caminho e a mulher indo depois ou junto, mas não como protagonista e central. Essa representação ainda alimenta consciências e é difundida por imagens midiáticas atuais.

Porém, no horizonte real, dos fatos, as estatísticas nos dizem que uma das características da imigração internacional dos últimos anos, é a presença intensa da mulher, assim como, em especial para a Europa, o motivo família ganha intensidade. Essa realidade não é explicada só pelo fato de legislações de alguns países permitirem o reagrupamento familiar, mas, também, devido ao fato de que ambos os sexos migram em proporções muito homogêneas. Homens migram também para reagrupar.

Esse fenômeno revela processos de maturação da realidade migratória, legislações que lhe deram algum favorecimento e interesse, bem como processos integrativos em termos sociais e no horizonte do trabalho.

A Itália é um desses casos e, é o que nos interessa nessa singela análise e tentativa de entendimento de alguns processos que orientam fluxos de brasileiros para o mesmo. As concessões de soggiorno (permissão para permanecer no país por um tempo) por motivo família cresceram em 10 anos (98-2008) em 216\%, enquanto que por motivo trabalho, que, em geral, é o que identifica mais as migrações, cresceu $88 \%$. Apenas, para ilustrar essa realidade, na França, por exemplo, e nos Estados Unidos, o motivo família esteve (2009) em 60 e 70\% das solicitações, respectivamente (CANEVA; CONIZZONI; AMBROSINI, 2009).

Aumentou em muito o número de mulheres que migraram nos últimos anos para a Itália; em 2000, a mesma atingia $46 \%$ do total global dos imigrantes. Em dezembro de 1999, num total de 1.252.994 soggiorni registrados, 46,3\% eram de mulheres. Esse índice vem aumentando; de 1994 a 2004, houve um incremento de mais de $35 \%$ no ingresso feminino no referido país; em 2008, o índice já subiu para 49,9\% (DOSSIER STATISTICO, 2009).

A imigração brasileira é uma das que possui maior participação feminina (56\%). Os imigrantes brasileiros na Itália, segundo os dados do Istat (Itália), estão na casa dos 50 mil, porém segundo o Itamaraty estão em torno de 130 mil. Essa diferença nos dados advém do fato de que os imigrantes que possuem a duplacidadania não têm necessidade de demandar regularização de sua situação no país, pois já são cidadãos europeus e/ou, no caso específico, italianos, portanto, não figuram como estrangeiros.

É comum a idéia de que "primeiro chegam os braços, depois chegam as famílias"; em geral, há o peso do contingente de mulheres que migram e reagrupam maridos, mas há os maridos que reagrupam mulheres como regra mais geral ainda (CANEVA; CONIZZONI; AMBROSINI, 2009). Nessas realidades, a presença de filhos passa a ser fundamental no interior da família.

No presente artigo $^{1}$ buscaremos relatar alguns processos dessa dinâmica, a legislação que lhes têm (aos imigrantes) possibilitado agrupar famílias, suas alterações, seus vínculos com a dimensão étnica, a segunda geração e suas repercussões no interior da família.

Teremos como espaço empírico, aspectos da imigração brasileira nas regiões Norte e Nordeste da Itália $^{2}$, espaços esses de nossa pesquisa de campo que estamos desenvolvendo. Estaremos analisando aspectos de uma lógica de transmigração em que os fatores de ordem étnica e familiar são de fundamental importância para a viabilização do processo.

\section{Informações Genéricas So bre Brasileiros no Norte/Nordeste da Itália}

Dos 268 questionários que nos foram retornados na região do Vêneto, em especial por imigrantes presentes em Verona, Vicenza, Treviso e Padova, por ocasião da última ida a campo em dezembro e janeiro de 2009, a maioria (72\%), é proveniente de regiões do Centro-sul do Brasil; idade média girando em torno de 27 a 35 anos, com preponderância ao redor de 28 anos (26 para as mulheres, 29 para os homens); 73\% trabalhavam de assalariado no Brasil, outros atuavam com a família tanto no espaço urbano quanto no rural em atividades variadas e em formas variadas, inclusive dentro da própria família. O grau de instrução média (segundo grau) é o que prepondera (81\%); apenas 12 informantes tinham grau superior completo, outros não informaram. A grande maioria se declarou solteiro(a) (69\%), 5\% divorciados, $23 \%$ casados, porém apenas 11 casos migraram com a família do Brasil; pouquíssimos filhos nasceram na Itália (apenas 6 de quatro famílias); $100 \%$ alugam a sua atual residência; 
julgam, em geral, possuírem um razoável enraizamento nos territórios de destino, porém fazem muitas ressalvas no tocante aos processos de integração, aceitação, concepção a cerca de serem brasileiros.

A grande maioria dos que responderam questionário (92\%) não havia ainda viajado para outro país; $82 \%$ emigraram sozinhos, porém $63 \%$ já possuíam conhecidos, parentes e/ou amigos emigrados; $12 \%$ foram amparados por redes de intercâmbio, gemellaggios (acordos entre cidades co-irmãs do Brasil e da Itália ligadas ao fenômeno imigratório do final do século XIX e início do século XX), ou outras formas de seleção anterior à emigração, a grande maioria emigrou a partir de vínculos com conterrâneos, amigos e parentes. Há, em meio aos brasileiros entrevistados, certas diferenciações em termos de concepção e simbologia pública no universo de inserção no trabalho bem como em sua correspondência com as diferenciações entre os imigrantes brasileiros em seu interior; há os descendentes (oriundi), os de duplacidadania, há os irregulares, os que estão aguardando os processos de regularização; há negros e brancos, há gaúchos, cariocas, bahianos..., os quais carregam para dentro do país hospedeiro estereótipos e imagens produzidas no país.

Desse modo, quando se fala em imigrantes brasileiros na Itália é bom que tenhamos sempre presente esse cenário de diferenciações. Estigmatizações, estereótipos e preconceitos se mobilizam também na construção da consciência do emigrante ao deixar sua terra de origem!

No campo do trabalho, o setor da construção civil, a agricultura, as atividades domésticas (limpeza e cuidados de saúde de idosos e de criança) são os espaços por excelência dos brasileiros. Para as mulheres, $79 \%$ informaram que estão em atividades domésticas (famílias e/ou em instituições de apoio social aos idosos e portadores de necessidades especiais), seja em limpeza e/ou cuidando de idosos em suas casas; em sete casos as imigrantes trabalham em restaurantes em atividades de limpeza em geral.

A grande maioria dos imigrantes acha que pelo fato de não estarem fazendo na Itália o que faziam no Brasil, no retorno ao país e, em geral, ao local de origem, também não farão o que fazem na Itália. Ninguém que é garçom na Itália se imagina sendo no Brasil; o mesmo vale para as domésticas, para os que trabalham na agricultura, nos aviários. Aliás, encontramos poucas respostas $(12 \%)$ indicando o desejo de permanência na atividade.

Há um desejo explícito em ser micro-empreendedor no espaço de proveniência, numa cidade maior (a cidade de Curitiba é muito mencionada pelos paranaenses, Joaçaba e Chapecó para os catarinenses;
Quadro 1: No momento, em que trabalhas?

\section{Atividades}

Agricultura

Construção civil

Espaço doméstico (cuidados)

Setor industrial

Espaço doméstico (limpeza)

Garçom

Limpeza em restaurantes e

bares

Aviários

Outros

Sem resposta

Total

\section{Número de casos}

78

61

47

33

31

5

3

3

3

4
Pesquisa de campo/2008/2009.

Caxias do Sul e Farroupilha para gaúchos). Há investimentos em gado no Brasil, muitos em imóveis 'para alugar', outros restaurantes 'aproveitando o que aprendi aqui', porém, em geral, o desejo de investimento é sempre no espaço de origem, em descobertas de nichos de mercado e/ou de atividades que, com certo desembolso inicial, são passíveis de rentabilidade satisfatória. A remuneração do trabalho, em comparação ao que se apresenta no Brasil, para praticamente todos os imigrantes $(96 \%)$ ), é o grande fator de atração; é o elemento motivador e compensador do 'tanto que agente se quebra e se judia aqui'. A intencionalidade de fundo é a dimensão econômica da permanência e do retorno.

Vimos que imigrantes brasileiros, há tempo (de dois a três anos em diante) localizados no país, exercem uma grande influência sobre os sucessivos desenvolvimentos do processo, servindo como ponte, interligação e cadeia. No campo dos negócios étnicos, o papel das redes de co-nacionais é muito importante; expressam-se, em muito na dimensão do gênero masculino, revelando, com isso, certa cultura social de que o homem é o provedor econômico, o qual foi socializado e exigido para tanto (AMBROSINI, 2003). Outra característica é que, além de masculina, são comumente jovens (83\%), talvez por serem também a maior expressão da faixa etária migratória. O horizonte empreendedor permite dar um salto de qualidade, ganhar mais, oportunidade de afirmação, adquirir posição de status aos olhos dos co-nacionais e dos italianos. Havia na Itália, em 2008, 1.656 empresas de 
imigrantes brasileiros; na região do Vêneto são 305 ; dessas, 243 estão construção civil, outras se diluem entre agricultura e serviços a pessoas (DOSSIER STATISTICO, 2009).

A presença de irregulares é significante entre os brasileiros e esse processo contribui ainda mais para que haja dificuldades na obtenção de trabalho, fato esse que faz com que muitos desses sofram os processos de exploração da força de trabalho pelos próprios conterrâneos e co-nacionais, habitem em geral em pequenas cidades do interior das províncias do Vêneto, espaços em que a vigilância é considerada menor e, há mais facilidade para alugar, bem como para encontrar trabalhos em geral na agricultura.

Enfim, aspectos da realidade de trabalhadores brasileiros revelam que o cenário é diverso, múltiplo, que há diferenciações e situações que fazem parte do cenário imigratório em geral no país. Talvez um elemento que carrega certa especificidade da imigração brasileira sejam as redes étnicas que foram se constituindo entre grupos políticos, associações, regiões etc. entre os dois países. É o que veremos melhor a seguir.

\section{Territórios Étnico-Culturais: a volta dos que nunca foram}

Imigrantes brasileiros possuem, de uma forma genérica, certa identificação com o território cultural do espaço de destino em razão de valores produzidos no ocidente, de concepções em torno do trabalho, da família e do uso do dinheiro, da descendência de muitos, etc. Há um capital social produzido pela descendência migratória que se acredita ter se reproduzido no lugar de destino dos processos migratórios de ontem e que se expressam na etnicidade que também migra. Desse modo, territórios étnicoculturais se produzem, reproduzem e se mobilizam com a dinâmica migratória.

Isso, muitas vezes, é levado em conta nos espaços de trabalho, na migração tutelada promovida por agencias, associações, políticas públicas, grupos étnicos presentes no interior da Itália (AMBROSINI; QUEIROLO PALMAS, 2005). Idealizações da Itália são produzidas em algumas regiões do Brasil, desejos e projetos produzidos no interior de famílias de muitos em viajar para a Itália e realizar o sonho dos pais e/ou nonos de retornar à terra natal. As identidades e identificações que são produzidas no interior das sociedades hospedeiras se constroem ou reconstroem pelos autóctones e estrangeiros também a partir desses referenciais simbólicos.

A dita 'emigração de retorno' (aos descendentes) é expressão de uma identidade de 'bons imigrantes'; em geral tende a ser auxiliada, beneficiada para retornar, pois são os considerados mais adaptados, os que, em teoria, terão melhor capacidade de assimilação e de serem assimilados para o trabalho, à dita e concebida genericamente cultura italiana. Não é incomum ouvir discursos políticos na Itália nesse sentido, aliás, pode se tornar produto de uma concepção política de cunho nacionalista.

Temos a impressão que essa dimensão do retorno dos oriundi ou do direito de retorno pode ser considerada um retorno dos que nunca foram/estiveram; são contextos de expressão distinta. Ainda que imigrantes sejam descendentes, seus horizontes culturais e espaciais são diversos. Como diz Kawamura, esses oriundi acabam sendo uma população que atende às necessidades raciais $\mathrm{e}$ ideológicas de esfera política, das demandas do mercado de trabalho como força barata, não qualificada e, de certa forma, controlada etnicamente (KAWAMURA, 2003).

Há uma tentativa de grupos em valorizar a chamada italianidade, uma italianidade 'secularizada', para não dizer burocratizada (pelos trâmites todos que envolvem a obtenção da dupla cidadania e os gemellaggios. Não é mais aquela da dita pátria-mãe, do sujeito que viajava com a 'mala de papelão', imigrante pobre, depreciado, estigmatizado, que se localizou 'in mezzo ai monti'.

A italianidade que se busca reconstituir por intermédio de grupos, associações, intercâmbios, gemellaggios, acordos de cooperação cultural, pela Lega Nord e seus difusores espalhados pelo Sul do Brasil, é aquela do sucesso obtido, da superação, da redenção, de uma Itália rica e de um Sul do Brasil também diferente do Norte/Nordeste, da pujança econômica dos italianos; enfim, não é uma memória de antigamente; não é do amor pátrio à antiga Itália; essa é até bom esquecer!

A imigração, desse modo, apresenta-se como um processo, como um fenômeno não-estático, construído socialmente por meio de interações entre grupos e forças sociais (imigrantes de etnias variadas, instituições públicas, políticas e jurídicas, o mercado de trabalho e agências recrutadoras de mão-de-obra); apresenta-se também como conexão entre níveis micro e macro da produção dos fenômenos sociais e dos processos que fazem a mediação entre aspectos estruturais e ações individuais (SALES, 1998). 


\section{Questões de Gênero no Processo Migratório}

Não são incomuns atribuições diferenciadas das causalidades que movem homens e mulheres ao processo migratório, em geral, identificando a mulher a motivações do campo afetivo e familiar (aqui os motivos nesse horizonte são variados). Porém, é bom que se enfatize que as mulheres, mesmo com dados demonstrando crescimento, continuam sendo quase invisíveis ou agrupadas nas mesmas dimensões que os homens, porém, em processo de dependência.

Diz Assis (2003) que a realidade da experiência migratória é atravessada por relações de gênero. As mulheres migram não apenas por razões econômicas; há elementos no campo das identidades e representações sociais que determinados grupos e sociedades produzem em torno da mulher e em especial da mulher trabalhadora, em geral no campo da discriminação e subordinação. Por isso que se compreende porque muitas mulheres migram sozinhas ou são as primeiras a migrarem em suas famílias. Quando são maridos que migram, esses auxiliam na transformação empreendedora da esposa, pois lhes confia o investimento e gerenciamento do dinheiro enviado, 'tocam a casa, os filhos ficam mais delas, não é porque tão tudo dia junto, por isso que não quero que ela trabalhe, pra que ela compense também minha ausência', como nos disse um migrante casado que deixou esposa e uma filha de três anos no Sul do Brasil. Indivíduos, instituições oficiais, mediações informais, grupos, demandas e ofertas vão produzindo espaços, criando vínculos, maximizando relações, definindo a identidade e/ou identificações de imigrantes trabalhadores (as) em situações heterogêneas. As mediações formais e informais são cada vez mais importantes e necessários em razão da própria situação-limite dos imigrantes. Não foram poucos os imigrantes que se aproximaram de nós por entenderem que, pelo fato de sermos professores, amigos de italianos e/ou amparados que éramos pela Universidade de Verona ou por entidades de igreja, poderíamos interceder junto a alguém para favorecêlos em alguma coisa, em geral, em torno do trabalho e moradia.

No tocante ainda ao trabalho doméstico, análises demonstram que, devido a oferta imensa de trabalhadores no setor e como forma de burlar a legislação do trabalho, está havendo uma passagem do trabalho fixo para o 'por hora' (part-time), acompanhado da independência habitativa, sendo essa com a família ou com pessoas outras (comumente conterrâneas).

Os baixos salários no país de origem, somados às condições de subalternizadas em vários campos sociais, a necessidade de acompanhar a rede familiar que migrou, dentre outros aspectos, fazem da emigração feminina uma dinâmica de forte intensidade e de pouco reconhecimento ou representação de identificação social. Talvez esse processo se deva ao fato de que, como diz Vicarelli (1994, p. 225):

ocupam os postos que nós temos deixado livres, fazem os serviços que não conseguimos intercambiar com nossos maridos, desenvolvem papéis que não temos conseguido que fossem organizados civilmente pelas estruturas sanitárias e pelos quais o voluntariado não tem suficientes braços e corações.

A força de trabalho feminina continua a ser vista como subsidiária com respeito às carências e flexibilidades que as agências e estruturas sociais apresentam. A sua presença, importância, significação, condição e demanda é muito expressiva da crise do estado social no tocante à assistência familiar, aos anciãos, aos portadores de deficiências, no trabalho de enfermeira. As mulheres adentram para o terceiro setor, para horários anômalos no comércio, nos restaurantes; apresentam-se como mulher e mãe num processo de reprodução de uma força de trabalho estrangeira cada vez mais estrutural na sociedade (DUSSI, 2000).

O exemplo a seguir é expressivo dessa performance: 'Faz dois anos que tô na Itália; sou filha de pequenos comerciantes em Criciúma, de uma família de cinco irmãos'. A entrevistada é formada em contabilidade, trabalhou em uma fábrica de calçados por nove anos em Criciúma. Perdeu o emprego e resolveu emigrar para a Itália. A decisão se deu pela insistência de um ex-namorado que já estava em Verona. Emigrou e ficou com conterrâneos nos dois primeiros meses até encontrar um trabalho em casa de família. Retomou o namoro e passou a viver na casa dos patrões, num andar superior da casa, local esse considerado como despensa e depósito - 'vivi um ano ou mais no meio de caixas, madeira, ratos e aranhas' -. Depois de alguns meses nessa situação, seu namorado a convidou para morarem juntos. Deixou a casa de família onde também trabalhava e passou a trabalhar por hora na mesma casa e em outras. Disse-nos que ganha menos, mas tem mais liberdade, pode até fazer bico (limpeza) em outras residências em tempos vagos. Seu desejo é casar 'no papel', obter a cidadania italiana, fazer um filho - 'minha idade [32 anos] não me permite esperar' -, ficar na Itália até o fillho começar a estudar e depois voltar - 'acho que daí, em dois, já 
fizemos o suficiente para viver bem, educar o filho para mais tarde, se ele quiser que venha para cá, claro, melhor do que nós'. Deseja sempre voltar para o local de origem, de sua família, de seu antigo trabalho, 'mas penso melhor e resisto à tentação, à saudade, à ansiedade também. [...]. Aqui não se tem companhia, tudo vira trabalho e há um medo agora de perder o emprego'. Narra conhecer muitos brasileiros desempregados; seu companheiro já esteve também por vários meses. 'Gostaria de convidar amigos, depois tu te envolve; não dá para convidar e deixar só; eu tive auxílio de conterrâneos, porém, quando fiquei irregular, me evitaram, tinham medo, fiquei sozinha meio que pra tudo". Enfatiza que no Brasil tinha deixado o namorado, mas na Itália passou a gostar 'Aqui muda tudo, tudo é diferente, eu, ele, as pessoas em geral, se precisa mais dos outros'.

A entrevistada diz que o fato de ser colf e baby sitter (faz limpeza e cuida de crianças) não se julga inferiorizada, porém, não quer fazer isso 'o resto da vida'; deseja ser valorizada no que diz saber fazer, mas tem a consciência de que isso é só no Brasil. 'Aqui é melhor nem dizer que tu é formada, te dão risada ou não acreditam, ou te tratam mal porque imaginam que queira largar o trabalho ou pedir aumento'. Quer voltar para ser valorizada, 'ainda que ele [o marido] não vá' depois de ter um filho. (Rosane, Criciúma, SC, dois anos na região do Vêneto - nordeste do país).

A presença de mulheres estrangeiras em trabalhos domésticos favorece a progressiva entrada das autóctones no mercado de trabalho, intensifica, no interior das famílias, as profundas mudanças culturais no interior das identidades de gênero no âmbito familiar/afetivo, colaboram para efetivar, no interior da sociedade hospedeira (e para eles), a refutação da chamada 'ideologia da domesticidade'. Tradicionais divisões de papéis entre homens e mulheres transferem-se em horizontes transnacionais, ao mesmo tempo em que emancipam mulheres do país hospedeiro da incumbência de atividades domésticas, de cuidados de saúde, no ingresso no mercado de trabalho extradoméstico. De certa forma, para o caso das imigrantes, paradoxalmente, também pode acontecer certo grau de emancipação fazendo trabalhos tradicionais no país de destino.

\section{Famílias Migrantes: ampliação de situações limites}

É por demais consolidada a idéia de que a imigração possui a família como elemento central, ainda que membros, isoladamente, são os que a materializam. A decisão da emigração, seu desenvolvimento, as problemáticas que a envolvem, a autorização de quem pode/deve emigrar, o retorno também, sustentação ético-afetivo, obrigação financeira e moral, vínculos, lealdade, etc., são todos elementos em que a família participa.

Com crise do sistema de welfare social principalmente em setores mais sensíveis como são as crianças e os idosos, o trabalho doméstico configurouse já como um componente estrutural do mercado de trabalho; é a chamada feminização no setor de serviços do mercado de trabalho (essa noção é criticada por muitos analistas pro desenvolver dimensões tradicionais de gênero no trabalho). $\mathrm{O}$ trabalho doméstico talvez seja expressão mais nítida da cadeia migratória, pois se constitui por familiares, amigas, vizinhas, parentes que se auxiliam em encontrar trabalho.

Vimos que brasileiras entrevistadas trabalham em grande quantidade em casas de família, residem com elas também; identificam o trabalho como de pouca autonomia pessoal, mas menos pesado, porém ressalvam que isso depende também de quem as contrata, da sua situação legal no país etc. As mesmas dão ênfase ao fato de exigirem emotividades, envolvimento afetivo, animação, ser/estar sempre alegre e de bom humor. As mulheres que não residem nas famílias expressam vantagens no sentido da desvinculação da convivência com patrões de uma forma mais estreita, revelam e buscam certa autonomia pessoal, têm seu espaço habitativo, 'sobra menos, temos mais custos, mas mais independência'. Elementos não econômicos passam a ser valorizados (autonomia, irregularidade, sem contratos, ganhos variados, - 'não me envolvo daí, né').

As mulheres, investidas do papel de reprodutoras da tradição, assumem a responsabilidade de sustentar o núcleo familiar no difícil momento migratório, favorecem o diálogo entre os diversos sistemas axiológicos, conciliam a diversidade étnica no interior de uma comum identidade humana. São as mulheres que, no fim, como sentinelas da comunidade, ou como catalizadoras das redefinições culturais, assumem, muito mais do que os homens, a gestão dos conflitos entre representações simbólicas do grupo e a prática induzida da nova realidade (DUSSI, 2000).

A presença das imigrantes faz com que as famílias italianas se livrem do "vile servizio", consigam atingir status de moderna referência; são as estrangeiras que cuidam da saúde de membros familiares, e não mais as mulheres em geral; são, sim, algumas mulheres e de um referido status social e de qualificação profissional. Há estudos que demonstram que a segunda geração de imigrantes talvez não queria esse tipo de trabalho, pois vai querer mais promoção e oportunidade da sociedade 
que acolheu seus pais.

A figura da badante, por exemplo, é muito desqualificada, despersonalizada (DUSSI, 2000); cuidar de idosos é considerado uma atividade árdua, convive-se num corpo a corpo, cara a cara com os idosos; muitas diferenças se produzem e se encontram nessa atividade: velho/jovem, pobre/rico, imigrante/nacionais, dormir na casa/trabalho, ou seja, acaba expressando uma situação/condição de vida e de trabalho ao mesmo tempo. Muitas vezes, essas mulheres abandonam seus pais (alguns deles já idosos) e filhos no local de origem e acabam cuidando dos idosos e crianças no espaço de trabalho no país de destino, relegadas a um nicho de trabalho desqualificado e associadas a uma imagem negativa de doméstica.

Ambrosini (2002) insiste nessa idéia de que as imigrantes operam no quadro da domesticidade, a qual já foi superada por grande parte das mulheres italianas; que as imigrantes são, em muitos casos, o único sustento e esteio do ancião; que a morte do idoso pode decretar perda de trabalho; que é interessante ter presente o sistema social italiano em seu dito 'welfare invisível', baseado nem trabalho pouco ou nada reconhecido ou retribuído; não esquecer da tendência ao envelhecimento da população, ao aumento de doenças crônicas, maior fragilidade da união familiar, aumento de pessoas que vivem sozinhas, aumento da presença feminina no trabalho fora de casa, a distância entre casa e trabalho para muitos autóctones e, mesmo para alguns imigrantes, as redes familiares pouco consistentes para o auxílio e sustento social e afetivo. As mulheres rearticulam, em escala migratória, os valores afetivos, familiares e o agregado doméstico, deslocam as funções de reprodução social que antes eram expressivos de contextos restritos: mulher, mãe, devoção familiar, transmissão afetiva, cuidados da saúde, maternidade, solidariedade, dádivas no interior da família etc. (DECIMO, 2005, p. 40).

Em determinadas circunstâncias e em certos âmbitos, as atividades consideradas subalternas e precárias para as mulheres italianas, pode ser uma possibilidade de emancipação para as imigrantes (requerer maior poder de decisão da mulher na família, transformando sua auto-estima, maior protagonismo e iniciativa).

Não me arrependo de ter ficado quatro anos em casa de família, aprendi muito; só que sei que não dá pra ficar sempre, tu não agüenta. Tu nunca tem tempo pra ti, nem um canto que seja teu a não ser o teu quarto, mas quem tu trás pro quarto? [...]. Tu acaba sendo tudo pros filhos, quem tem né. Eu tinha de cuidar de dois e um idoso que depois morreu. A gente na casa é tudo, faz tudo, te deixam pra fazer tudo, compras, levando filhos pra cá e pra lá, telefonam toda a hora pra saber uma coisa ou outra. [...] Com o tempo, tu quer coisa melhor, onde tu se vira, mas tu já tem experiência né, já fez uns contatos, já ta no país há um bom tempo como era теи caso né. [...]. Meu sonho é bota uma lojinha de produto brasileiro, o pessoal adora tudo o que se mostra do Brasil. (Rosângela, oriunda de Guarapuava - PR, quase três anos na Província de Treviso; entrevistada em 2009).

Deixar esposa e filhos, ou deixar marido e filhos, deixar filhos com avós, deslocar toda a família para espaços novos significa produzir processos de rompimento, redefinições, nostalgias, preocupações, novas experiências, novos desafios, desejos de permanência e de retorno, produzir distanciamentos (amigos, parentes, outros vínculos afetivos) e novas aproximações, solidão, isolamento social, novas relações sociais; faz repensar o conceito de família (comumente mais heterogênea) (DUSSI, 2000).

\section{Dimensões Transnacionais}

As famílias exercem uma função ativa no cenário migratório: reinventam formas de vida e de autoorganização, adaptam-se ao novo contexto, questionam e/ou readaptam valores de tradicionais sistemas familiares (monogenitorialidade, separações e reagrupamentos). Esses processos de reconstrução obedecem às condições efetivas e limitadas que o próprio cenário migratório apresenta. Mas, ao mesmo tempo, redimensionam as fronteiras das famílias, ou seja, essas passam, pelo menos em parte, ser 'transnacionais', pois têm seu vivido em mundos diversos, especialmente o expresso pelo feminino, que precisa afrontar tradições (já que no passado eram, em geral, os homens que migravam), contatos com os filhos através de viagem (custos altos e viagens longas), cartas, telefone, e-mails.

Imigrantes brasileiros, pais entrevistados em algumas cidades do norte e nordeste da Itália, têm clareza que os bens materiais não compensam as ausências de afeto/amor ocasionados pela presença física, mas 'demonstra que os amamos e que estamos aqui por eles'. É até meio paradoxal, mas é visível que a segurança financeira caminha concomitante com a insegurança afetiva. Ganhar mais significa possibilidade de permanecer mais tempo, comprar 
mais coisas aos filhos, idealizar melhores condições de vida aos mesmos e, maior distância; ou, então, pode também acontecer que, com melhores condições econômicas, haja possibilidade de reagrupar a família no espaço imigratório.

O que se evidencia é que há uma grande dinâmica entre famílias de imigrantes que vai produzindo processos transnacionais: mães que vivem a experiência da maternidade e conjugalidade à distância, as remessas ligando também essas dimensões (envio, gerenciamento, responsabilidade financeira etc.). Essa realidade envolve interação entre os dois espaços (origem e destino), integração simultânea ou não, comunicação à distância, que permite manter relações afetivas sem mobilidade e encontro físico (BOCCAGNI, 2007).

Nesse horizonte relacional, vínculos continuam persistindo bem como intimidade e afetividade à distância facilitadas pelas novas tecnologias de comunicação. Nesse sentido, a imigração faz ver a importância da família na sociedade, faz ver como ela é, seus elementos variados de reprodução, sua importância, suas várias roupagens e recomposições, seus traumas e desafios, seus recursos estratégicos no além-fronteira e nos limites da presença física (BALSAMO, 2003).

Através da família, a imigração revela sua forte dimensão relacional, sua obrigação para com o todo 'melhorar a vida dos filhos', 'dar um melhor futuro pra eles', é o que mais se houve dos pais. A história da família se revela nas relações que emigração produz. Quem tem mais vínculo moral e econômico com a família a transforma em seu centro de vida mesmo distante. Alguns pais que entrevistamos revelam o temor da perda e/ou erosão da cultura do espaço de origem, das relações de pertencimento. A provisoriedade na Itália, ou pelo menos enquanto projeção da mesma produz um sentimento de ausência de pertencimento no espaço migratório; isso impede processos de assimilação, de inserção nos dois mundos (origem e destino). Porém, a presença de filhos nas famílias de imigrantes, em geral, tende a alterar projetos de permanência por pouco tempo, assim como a própria cultura familiar (SCABIBI; DONATI, 1993). Essa realidade de partir para retornar produz essas dimensões transnacionais mais fortemente.

O reagrupamento familiar, por tornar-se um fator que favorece a vida familiar, pode também ser reprodutivo de incertezas e imprevisibilidades, incompreensões, conflitos e tensões cotidianas que o próprio novo cenário produz e que há dificuldades de solução. Não é incomum haver retorno de filhos e/ou de algum dos cônjuges em razão de conflitos produzidos no espaço migratório e, daí como nos disse o mesmo pai acima, 'tudo o que se fez cai por terra, se pensava em melhorar a família e acaba se desfazendo tudo'. Tanto a separação quanto a reaproximação são realidades por si só problemáticas.

\section{Novas Exigências}

Análises demonstram que pais que migram sem seus filhos tendem a desenvolver mais o desejo de retornar em seu projeto migratório. A dimensão da provisoriedade da identidade de imigrante produz um conjunto de relações que se produzem quase que simultaneamente entre os dois espaços.

Alguns pais que entrevistamos revelam o temor da perda e/ou erosão da cultura do espaço de origem, das relações de pertencimento. A provisoriedade na Itália, ou pelo menos enquanto projeção da mesma, produz um sentimento de ausência de pertencimento no espaço migratório; isso impede processos de assimilação, de inserção nos dois mundos (origem e destino). Porém, a presença de filhos nas famílias de imigrantes, em geral, tende a alterar projetos de permanência por pouco tempo, assim como a própria cultura familiar (SCABIBI; DONATI, 1993). Essa realidade de partir para retornar produz essas dimensões transnacionais mais fortemente.

As situações difíceis pelas quais passam as crianças que tiveram seus pais ausentes fazem com que se torna difícil a compreensão e o argumento de que esses (os pais) estejam se sacrificando por elas. Os pais são compreendidos de uma forma negativa, como ação egoísta e individualista. 'Eles não entendem, claro, sentem nossa falta. [...]. Um dia eles vão entender; se eles um dia vierem pra cá, já, por causa nossa, não vão passar o que nós passamos. Isso a gente que ta aqui enxerga, eles não ainda'. Vários pais nos disseram que se sacrificam por eles, mas não são agora compreendidos, "entenderão mais tarde".

O reagrupamento familiar poderá, talvez, amenizar esse problema, porem há um grande impacto do reencontrar-se; sem dúvida, não é algo natural e calculado, que tudo se possa previamente programar. Horizontes de afetividade são complexos; se os pais e filhos ficaram alguns anos separados, mundos paralelos foram se constituindo, socializações não esperadas ou não programadas também se construíram. O reagrupamento entre imigrantes brasileiros é considerado baixo. Uma das explicações é a dificuldade de poupar tendo os filhos juntos, exigências burocráticas, redefinições amplas que acabam acontecendo e alterando o projeto migratório original. No reagrupamento, os filhos enfrentarão uma realidade não esperada, ou seja, a de que seus pais fazem parte da escala social mais baixa; as 
idealizações anteriores se rompem. A ausência de suporte social e mesmo de capital social que a identidade de imigrante carrega vai revelar isso aos filhos.

Dependendo da quantidade de tempo que filhos permanecem na Itália, os faz perder as referências com o local de origem. Quem nasce na Itália, é comum que não desenvolva referenciais de pertencimento com a sociedade de origem de seus pais. Nessas circunstâncias o projeto migratório se altera muito; em geral, os filhos não querem voltar com seus pais para o local de origem desses. Um pai nos disse que tem medo

que ele não queira voltar depois e, eu te confesso, não pretendo terminar meus dias por aqui; se ele quiser vir sozinho quando crescer mais, tudo bem, é conta dele; mas estando aqui muda a cabeça e fica tudo mais difícil. Aqui se muda viu.

O reagrupamento familiar, por tornar-se um fator que favorece a vida familiar, pode também ser reprodutivo de incertezas e imprevisibilidades, incompreensões, conflitos e tensões cotidianas que o próprio novo cenário produz e que há dificuldades de solução. Não é incomum haver retorno de filhos e/ou de algum dos cônjuges em razão de conflitos produzidos no espaço migratório e, daí como nos disse o mesmo pai acima, 'tudo o que se fez cai por terra, se pensava em melhorar a família e acaba se desfazendo tudo'. Tanto a separação quanto a reaproximação são realidades por si só problemáticas.

Tanto no local de origem quanto se estiverem reagrupadas, são as mulheres as que mais se responsabilizam pelo cuidado dos filhos; o uso do telefone, as remessas enviadas, o retorno mais seguido das mesmas para verem os filhos. A dimensão da sensibilidade genitorial é mais presente e intensa nas mulheres. Um marido nos disse que a sua mulher o pressiona toda a vez que liga tanto para enviar dinheiro como para retornar o mais breve ou, então, para decidir buscá-los todos para ficar juntos na Itália - 'pensam lá que é fácil aqui, que é só ir lá e trazê-los; aqui tudo é difícil é conseguido com muito trampo e sacrifício; eu também gostaria, mas não é assim'.

Muitas mães, com a possibilidade de fazer reagrupar filhos, alteram seu horizonte de trabalho ou do tempo do mesmo. Sempre houve na realidade imigratória italiana uma certa 'familiariazação' dos imigrantes no interior das famílias. Com a presença de filhos isso se altera; é um percurso complexo de relações, obstáculos, imprevisões, retornos e reentradas. Por isso que nem todos que possuem a possibilidade legal de reagrupar, reagrupam.

Em geral, pais entrevistados dizem que essa possível realidade de agrupamento aumenta demais a necessidade econômica, exige uma nova gestão da vida em família e do cotidiano de trabalho, de fora dele, do ritmo da vida, habitação, o problema do processo integrativo de adolescentes, escola, língua e lazer. A falta de controle e autonomia sobre esses processos todos, os burocráticos também; medo de separação total em razão dos limites, da estrutura de vida em casa, da necessidade de ampliar ganhos, do trabalho exaustivo; 'do fato que depois, um quer voltar e o outro não, aí vira em separação, como já vi brasileiro aqui assim'. Insistimos nisso, pois é uma realidade bem visível entre brasileiros com direito a lei do reagrupamento familiar e, não o fazem.

\section{Enfim...}

Há ordens variadas entre pais e filhos quando o reagrupamento se viabiliza. Cada situação reserva pra si complexidades. Um adolescente, há meio ano em Verona com seu pai, informou-nos que se sente numa situação ambígua em termos de identidade: não se sente brasileiro em meio aos brasileiros e, também, não se sente italiano em meio aos italianos; ou então, que há desejo de voltar, mas tudo o que é feito na Itália é para permanecer; seu pai cobra do mesmo a integração e relação com brasileiros, mas ao mesmo tempo, o insere nos universo de italianos (escola, cursos extra-classe, lazer, etc.).

Não há dúvida que as questões de gênero são importantes na configuração dos fluxos migratórios: mercado salarial, filhos no interior do grupo doméstico, hierarquia e desigualdade, sustentação, mediação e proteção. Encontramos algumas brasileiras que eram casadas e emigraram para a Itália deixando esposo e algumas delas os filhos no país.

Oh, se te contá! Foi uma decisão difícil, mas encarei; não estavam bem as coisas entre nós [marido]; duas vizinhas vieram e me mandei também. [...]. Meu marido me fez propostas e mais propostas, inclusive de acabar com tudo, mas e os filhos? Enfrentei; convenci ele que seria para experimentar e depois eu levaria todos, que seria melhor pra nós e mais futuro pros filhos. A gente pensa sempre neles também. [...]. Hoje sei que acertei porque ele entende; já faz sete meses e tamo pensando em vir todos pra cá, tenho saudade, mas aprendi muita coisa, amadureci e queria 
que meu marido e filhos fizessem o mesmo. (A entrevistada preferiu não ser identificada, oriunda de SC).

O depoimento demonstra a esfera familiar como espaço de conflito e de negociação, hierarquias e desigualdades, estratégias de afrontamento da autoridade masculina e de superação de papéis no seio doméstico-familiar. A entrevistada deixa claro que afrontou e/ou enfrentou a autoridade masculina, vinculou-se a redes de vizinhança e amizade e selou a proposta de, com o passar do tempo, incorporar o marido e filhos no projeto efetivo da imigração.

Os cônjuges, em geral pais, alteram seus códigos estabelecidos, principalmente os que legitimam papéis definidos de dominação, de opressão de gênero (DECIMO, 2005). Não é fácil, como uma imigrante nos disse, 'estar fora e querer tomar comando da casa, temos de abrir mão disso; se perde alguma coisa e se ganha em outra'.

Um entrevistado que nos informou uma residência vizinha da sua em que a mulher "deixou o marido e se mandou pra Itália”, disse-nos que:

Tu já pensou de uma hora pra outra ela [mulher] me diz, "olha, toma conta de tudo que eu to indo com a fulana de tal pra Itália”; foi o que aconteceu com o [nome do vizinho]. Tu já imagina uma coisa dessas? Mas te digo que foi o que aconteceu. Ainda que aqui, como tu mesmo disse, tem muita gente saindo, é normal ouvir falar de gente que vai e gente que volta. Mas, te digo que $o$ vivente ficou sem saber como reagir, claro que não aceitou, mas tu sabe, ela quis ir junto com a irmã, tinham certo que era pra poucos meses, tudo arrumado lá, trabalho, essas coisas, não, de outras, né que já tavam lá. Eu sei que se é comigo não deixo nem por quanto dinheiro for; tu fica mal visto, vai lá sabê o que se passa por lá, porque tu sabe que esse negócio de só uns meses, é conversa, vão e não voltam já, ficam atraída pelo dinheiro e pela vida nova, sem os compromisso da família. Foi assim que aconteceu aqui e, não são poucos que deixaram o marido, ou os pais, namorado e se mandaram. (Entrevistado de Criciúma, $S C$ ).

Os maridos se sentem desprestigiados em sua identidade econômico-simbólica de pai/esposo. A simbologia do sucesso e prestígio recai sobre a emigrante e, não sobre quem fica. A promessa de recomposição da família, do futuro melhor para os filhos racionaliza e legitima separações físicas temporárias, porém como mulheres na Itália e maridos de outras no Brasil nos informaram, 'muita coisa muda; a distância e a saudade faz a gente pensar se vale a pena. Os filhos crescem e tu abre mão disso, a vida em família, pelo sonho de ganhar mais dinheiro; é uma vida desgraçada nesse ponto viu'.

Nesse horizonte, estão em jogo múltiplos processos, dentre eles a transnacionalização dos papéis reprodutivos e de gênero em especial no espaço do trabalho (nesse campo a migração não altera grandes coisas), reafirmação e/ou redefinição de status, perda desse, assim como prestígio social, notoriedade, poder, delegações a terceiros no cuidado de filhos, na vigilância em torno da fidelidade conjugal, a domesticidade, machismo etc. No fundo, tudo isso está presente e dinamizando situações e decisões.

As questões de gênero são importantes na configuração dos fluxos migratórios: mercado salarial, filhos no interior do grupo doméstico, hierarquia e desigualdade, sustentação, mediação e proteção. A esfera familiar deve ser entendida como espaço de conflito e de negociação, hierarquias e desigualdades, estratégias de afrontamento da autoridade masculina e de superação de papéis no seio doméstico-familiar. Em pesquisa de campo, constatamos algumas famílias em que a mulher emigrou, outras que posteriormente se incorporaram na Itália, outras que se divorciaram em razão da imigração e/ou emigraram devido ao falimento do casamento. Vimos que realmente poucos maridos aprovam a emigração da esposa, ainda que as remessas financeiras sejam demandadas e importantes. Os cônjuges, em geral pais, alteram seus códigos estabelecidos, principalmente os que legitimam papéis definidos de dominação, de opressão de gênero (DECIMO, 2005).

A característica de base que relaciona a mulher no horizonte da imigração é a sua ligação com o serviço doméstico em famílias e, em segundo, em restaurantes e ofícios públicos, em terceiro nas empresas. Isso está presente tanto nos grandes centros, como nas regiões ricas do Norte/nordeste da Itália. Autores (DE FILIPPO, 2000) colocam algumas outras características da presença desse trabalho considerado de gênero, dentre elas, trabalhos pouco regulamentados, de intensa flexibilização temporal e espacial, e, alguns casos, como o de residência, de turnos mais elásticos, variabilidade de remuneração em termos de tipo de contrato, da nacionalidade de origem, da vizinhança cultural da mediação quando da contratação de trabalho (parentes, amigos, 
cooperativas de trabalho).

Enfim, muitas mulheres emigram, aliás, sempre emigraram, com famílias e individualmente. Nas últimas décadas, esse processo, talvez, tenha se intensificado tendo em vista um contexto de proliferação de pequenas empresas, de serviços com certa identificação tradicional de gênero como é o caso das colf, badante e baby sitter. Porém, alguns autores (HOCHSCHILD, 2004) colocam que, não obstante os índices identificarem grande fluxo de mulheres imigrantes para a Itália, permanecem e/ou pouco se alteram relações que hierarquizam, etiquetam e discriminam as mulheres na sociedade de destino (aparência física, língua, país de procedência, raça...) e que, também, as famílias são o elemento central.

1 O presente texto foi escrito para servir de base a uma apresentação que fizemos no Seminário Fazendo Gênero, realizado em agosto de 2010 na UFSC.

2 Pequisamos desde 2002 aspectos da realidade da emigração brasileira para a Itália, dando ênfase aos fenômenos étnicos, as associações de intercâmbio, o papel das igrejas, as redes formas e étnicas que foram se constituindo, bem como a dinâmica das relações de trabalho. As pesquisas de campo aconteceram todos os anos desde 2002, em períodos de um a dois meses (em geral de dezembro a fevereiro, período de nossas férias acadêmicas) e se centraram nas regiões Norte e Nordeste do país por haver uma maior concentração de imigrantes e uma maior participação e mediação dos horizontes de cunho étnico (redes informais e formais, vínculos, acordos, gemellaggios, intercâmbios etc.). As publicações em livros que resultaram dessa pesquisa encontram-se na bibliografia do final do texto.

\section{Referências}

AMBROSINI, Maurizio. Puntelli stranieri alle famiglie italiane. In: Famigila Oggi, $\mathrm{n}^{\circ} 12$, ano XXV, Diccembre, p. 8-13, 2002.

AMBROSINI, Maurizio; QUEIROLO PALMAS, Luca. Ilatinos alla scoperta della Europa. Milano: Franco Angeli, 2005.

ASSIS, Gláucia de Oliveira. 'De Criciúma para o mundo': gênero, família e migração. Revista Campos. Curitiba, p. 33-49, 2003

BALSAMO, Franca. Famiglie di migranti: trasformazione dei ruoli e mediazioni culturali. Roma: Carocci, 2003.

BOCCAGNI, Paolo Il. Trasnazionalismo, fra teoria social e orizzonti di vita de migranti. Rassegna Italiana di Sociologia. Roma, p. 519-540, 2007.

CANEVA, Elena; CONIZZONI, Paola; AMBROSINI, Maurizio. Ritrovarsi altrove. Famiglie e ricongiunte e adolescenti di origine immigrata. Milano: Fondazione ISMU, 2009.

DE FILIPPO, Elena. La componente femminile dell'immigrazione. In: PUGLIESE, Enrico. (a cura di). Rapporto immigrazione. Lavoro, sindacato, società. Roma: Ediesse, 2000, p. 47-63.

DE VINCENTI, Antonella Marcucci. Le badanti: um nuovo mestiere: In: La Critica Sociologica, $n^{0} 1, p$. 91-97, 2009.

DECIMO, Francesca. Quando emigrano le donne. Bologna: Il Mulino, 2005.

DOSSIER STATISTICO 2009. Caritas de Roma, 2009.

DUSI, Paola. Flussi migratori e problematiche di vita sociale. Verso una pedagogía dell'intercultura. Milano: Vita e Pensiero, 2000.

GOZZIN, Giovanni. Le migrazioni di ieri e di oggi. Una storia comparata. Milano: Mondadori, 2005.

HOCHSCHILD, Arlie. Russell. (a cura di). Donne globale: tate, colf e badanti. Milano: Feltrinelli, 2004.

KAWAMURA, Lili. Para onde vão os brasileiros? Imigrantes brasileiros no Japão. Campinas: Unicamp, 2003.

SALES, Tereza. (et al). O fenômeno migratório no limiar do terceiro milênio: desafios pastorais. Petrópolis: Vozes, 1998.

SCABIBI, Eugenia.; DONATI, Pierpaolo. (a cura di). La famiglia in uma società multietnica. Milano: Vita e Pensiero, 1993. 
O Gênero na Imigração: Redefinições de Papéis e

Dinâmicas Étnicas

VICARELLI, Giovanna. (a cura di). Le mani invisibile. La vita e il lavoro delle donne immigrate. Roma: Ediesse, 1994. 